\title{
Lider-Üye Etkileşimi ile Performans Arasındaki İlişkinin İncelenmesi: Bir Meta-Analiz Çalışması
}

\section{Examining the Relationship between Leader-Member Exchange and Performance: A Meta-Analysis Study}

\author{
Dr. Öğr. Üyesi Yener AKMAN ${ }^{1} 1$
}

\begin{abstract}
$\ddot{O} \mathbf{z}$
$\mathrm{Bu}$ çalışmanın amacı lider-üye etkileşimi ile performans arasındaki ilişkiyi meta-analiz yöntemi ile incelemektir. Bu amaçla çalışmada yer alan araştırmaların bireysel ve genel etki değerleri hesaplanmıştır. Çalışma grubunu, 01.01.2000-31.12.2020 tarihleri arasında Türkiye'de yayımlanmış lider-üye etkileşimi ile çalışan performansı arasındaki ilişkiyi inceleyen 23 bağımsız tez ve makale oluşturmaktadır. Çalışma grubunun katılımcı sayısının 7695 olduğu görülmüştür. Bu çalışmalara Yüksek Öğretim Kurulu Ulusal Tez Merkezi, ULAKBIM Ulusal Veri Tabanı ve Google Akademik üzerinden ulaşılmıştır. Meta-analizde yer alan araştırmalarda örneklem büyüklüğü ve Pearson korelasyon katsayı (r) değerlerinin olmasına dikkat edilmiştir. Araştırmaların etki büyüklükleri rastgele etkiler modeline göre belirlenmiştir. Analiz sürecinde CMA 3.0 programı kullanılmıştır. Çalışma bulgularına göre lider-üye etkileşimi ve çalışan performansı arasındaki ilişkinin pozitif yönlü ve orta düzeyde $(r=.44)$ genel etki büyüklügüne sahip olduğu görülmüş̧ür.
\end{abstract}

Anahtar Kelimeler: Lider-üye etkileşimi, performans, korelasyon, meta-analiz

Makale Türü: Araştırma

\begin{abstract}
The purpose of this study is to examine the relationship between leader-member exchange and performance with meta-analysis method. Accordingly, individual and general effect values of the studies were calculated. The study group has been formed 23 independent theses and articles which examined the relationship between the leader-member interaction with employee performance published between the dates 01.01.2000-31.12.2021 in Turkey. It was observed that the number of participants was 7695. These studies have been accessed through Council of Higher Education National Thesis Center, ULAKBIM National Database and Google Scholar. It was paid attention to have sample size and Pearson correlation coefficient ( $r$ ) values in the studies. The effect sizes of the studies were determined according to the random effects model. CMA 3.0 program was used in the analysis. According to the findings, it was observed that the relationship between leader-member interaction and employee performance had a positive and medium level $(r=.44)$ overall effect size.
\end{abstract}

Keywords: Leader-member exchange, performance, correlation, meta-analysis

Paper Type: Research

Giriş

Örgütsel etkililiğin en önemli unsurlarından birinin insan kaynakları arasındaki ilișkinin niteliği olduğu savunulabilir. Alanyazında lider ile çalışanlar arasındaki ilişkiyi inceleyen kuramlardan biri de lider-üye etkileşimi (LÜE) kuramı olarak belirtilebilir. LÜE kuramı, liderin diğer çalışanlarla her zaman eşit ve tutarlı ilişkiler kurmadığını öne sürmektedir (Schriesheim, Neider, Scandura ve Tepper, 1992). Bu kuram lider ile çalışanlar arasında sürekli bir sosyal

${ }^{1}$ Süleyman Demirel Üniversitesi, Eğitim Fakültesi, yenerakman@sdu.edu.tr

Atıf için (to cite): Akman, Y. (2021). Lider-üye etkileşimi ile performans arasındaki ilişkinin incelenmesi: Bir meta-analiz çalışması. Afyon Kocatepe Üniversitesi Sosyal Bilimler Dergisi, 23(4), 1308-1321. 
değişimin olduğunu işaret ederken liderin takipçileri ile farklı düzeyde ilişkiler içerisine girebileceğini vurgular (Dulebohn, Bommer, Liden, Brouer ve Ferris, 2012). Diğer bir ifadeyle kişiselleştirilmiş ilişkileri öne çıkarmaktadır. LÜE çalışmaları genellikle lider ile izleyenler arasındaki etkileşimi grup içi ve grup dışı olmak üzere ikili olarak ele almıştır. Kimi araştırmacılar ise örgüt içerisinde LÜE'nin yüksek ve düşük ilişkili gruplar şeklinde bir sinıflandırma oluşturduğunu belirtmiştir (Graen ve Uhl-Bien, 1995). LÜE'de lider kimi çalışanlara daha fazla kaynak sağlarken kimilerine ise daha az kaynak sunabilir. Bu durumun lider ile üye arasındaki ilişkiyi etkileyerek bireysel ve örgütsel çıktıların farklılaşmasına neden olacağ 1 düşünülebilir. Yani kaliteli lider-üye ilişkisinin olduğu örgütlerde daha olumlu çıktılar ve daha az iş bağlantılı sorunlarla karşılaşılmıştır (Wang, Xu, Liu ve Jiang, 2015). Zaten yüksek kaliteli lider-üye etkileşiminin olduğu örgütlerde çalışanların liderin daha fazla zamanını, rehberliğini ve duygusal desteğini alırken düşük kaliteli ilişkiler ise iş tanımının gerekliliklerinden öteye gitmeyerek daha resmi ilişkiler kurulmaktadır (Uhl-Bien, Graen ve Scandura, 2000). Benzer olarak Graen ve Uhl-Bien (1995) de, yüksek kaliteli LÜE ilişkilerinde lider ve çalışanlar arasında karşılıklı güven, saygı ve mesleki bilincin geliştiğini ifade etmektedir. Ayrıca çalışanlar lider ve grup içi üyeler tarafindan desteklenirken sadık ve güvenilir olarak nitelendirilir. Ancak alan yazında LÜE'nin örgüt ve çalışanlar üzerinde durumsal olarak olumlu ya da olumsuz çıktılara sebep olduğu da görülmüştür (Wang, Chen, Lu, Eisenberger ve Fosh, 2018). Şöyle ki LÜE, örgütsel vatandaşlık gibi olumlu karşılıklı davranışların gelişimini sağlarken, kimi çalışanlar açısından ise iş yerine karşı olumsuz tutumların artmasına da neden olabilir (Martin, Guillaume, Thomas, Lee ve Epitropaki, 2016).

LÜE'nin gelişiminde rol kuramı ve sosyal değişim kuramı (Blau, 1964) gibi kuramların etkisi görülmektedir. Bu kuramlar bağlamında örgütlerde LÜE'nin incelenmesi için çeşitli modellerin önerildiği görülmüştür (Dienesch ve Liden, 1986; Gerras, 1992; Liden ve Maslyn, 1998). Özellikle 2000'li yıllardan sonra gerçekleştirilen çalışmalarda Liden ve Maslyn'in (1998) önerdiği dört boyutlu modelin araştırmacılar tarafından yoğun şekilde kullanıldığ 1 ifade edilebilir. Bu modelde LÜE etki, katkı, vefakârlık ve profesyonel saygı olmak üzere dört boyutlu olarak ele alınmıştır. Etki, taraflar arasındaki karşılıklı ilişki ile ilgili olurken; katkı da tarafların sergilediği eylemlerin miktar ve niteliğini işaret etmektedir. Vefakârlık taraflar arasında koruma-destekleme bağlamında vefanın derecesi iken profesyonel saygı ise tarafların örgütteki saygınlığının derecesini belirtmektedir.

Alan yazında LÜE'nin özel sektör ve kamu kurumlarında farklı örneklemler ve değişkenlerle olan ilişkisinin incelendiği görülmüştür. Bu çalışmalarda kavramın iş doyumu (Harris, Wheeler ve Kacmar, 2009), örgütsel vatandaşl1k (Çetin, Korkmaz ve Çakmakçı, 2012; Huang, Wang ve Xie, 2014; Tekin, 2018), örgütsel bağlllık (Alev ve Taş, 2020; Ariani, 2012; Çalışkan, 2018), öz yeterlilik (Khorakian ve Sharifirad, 2019), sosyal destek (Lee, Thomas, Martin ve Guillaume, 2019), özdeşleşme (Akman, 2017), iş özerkliği (Volmer, Spurk ve Niessen, 2012), lidere güven (Scandura ve Pellegrini, 2008; Tastan ve Davoudi, 2015), işle bütünleşme (Meng ve Wu, 2015), öğretmen liderliği (Öztürk ve Şahin, 2017), adalet (Turgut, Tokmak ve Ateş, 2015) gibi bireysel ve örgütsel çıktılar üzerindeki etkileri çözümlenmiştir. Değinilen ifadeler LÜE'nin oldukça geniş bir perspektiften ele alındığı izlenimi bırakmaktadır. Özellikle uluslararası alan yazında kavramın uzun zamandır inceleniyor olması çalışan performansı ile olan ilişkisinin daha ayrıntılı ve farklı bağlamlarda irdelenmesini sağlamıştır. Uluslararası çalışmalarda LÜE ile performans ilişkisi çoğunlukla hem boyutsal hem de çift yönlü olarak araştırılmıştır. Şöyle ki LÜE'nin mi performansı artırıp/azalttığı yoksa çalışan performansının LÜE'nin gelişimini mi sağladığı tartışmaları göze çarpmaktadır (Mazur, 2012; Michael, 2011). Ayrıca performansın bir bütün olarak değerlendirilmesinden ziyade görev performans1, gönüllülük performans1 ve zarara yönelik performans üzerinden araştırıldığ 1 görülmektedir. LÜE üzerine yapılan analizler arasında dikkat çeken bir nokta da çoğu araştırmacının aksine Shore, Tetrick, Lynch ve Barksdale'in (2006), LÜE'ye ekonomik değişim iliş̧kilerini de eklemesi olmuştur. Bu durum LÜE'nin hem sosyal hem de ekonomik bağlamda ele alınabileceğini işaret etmiştir. Aslında alan yazındaki çoğu araştırmanın LÜE'yi sosyo- 
duygusal bağlamda incelediği görülmüştür. Sosyal LÜE ilişkilerinde daha uzun zaman yönelimli sosyo-duygusal bir ilişki vurgulanırken; ekonomik LÜE ilişkilerinde ise belirli bir zaman periyodunda anlık kişisel çıkarlara odaklanılmaktadır (Walumbwa, Cropanzano ve Goldman, 2011).

LÜE'nin sıklıkla birlikte ele alındığı kavramlardan biri de çalışan performansıdır (Agarwal, Datta, Blake-Beard ve Bhargava, 2012; Anand, Hu, Vidyarthi ve Liden, 2018; Graen ve Uhl-Bien, 1995; Harris vd., 2009; Quade, McLarty ve Bonner, 2020). Performans, bir amaca ulaşabilmek için ortaya konulan çabanın ölçülmesi olarak tanımlanabilir (Bilgin Yurdaöz, 2018). Tutar ve Altınöz (2010) ise performansı, herhangi bir etkinliğin gerçekleştirilme düzeyi olarak belirtmiştir. Diğer bir ifadeyle performans, çalışanın örgütteki verimliliği ve etkililiğ olarak ele alınabilir. $\mathrm{Bu}$ doğrultuda bir örgütün amaçlarına ulaşmasında çalışanların bireysel performansının önemli rol oynadığı düşünülebilir. Performans düzeyinin ise çeşitli unsurlar tarafından etkilendiği bilinmektedir. Bunlar arasında çalışanların kişisel özellikleri ve mesleki yeterlilikleri olabileceği gibi örgütteki ilişkiler ağ 1 ve çevresel faktörler de olabilir. Bu süreçte liderlik davranışlarının performans üzerinde etkili olduğu çeşitli çalışmalarla desteklenmiştir (Arar ve Abu Nasra, 2019; Bass, 1985; Wang, Law, Hackett, Wang ve Chen, 2005).

$\mathrm{Bu}$ konuda, Avolio ve Bass (1995) iş performansının çoğunlukla çalışanların kişisel özellikleri ve yetenekleri ile ilgili olsa da çalışanların bunları eyleme dökebilmesi ve geliştirebilmesinde liderin önemli bir rol oynadığını belirtmiştir. Lider ile uyumlu ilişkiler kuran çalışanların örgütsel kaynaklara daha kolay ulaşacakları ve performanslarını artıracakları düşünülmektedir. Zaten çalışan performansı üzerine yapılan çoğu araştırmanın temellendirildiği dönüşümcü liderlik teorisi (Bass, 1985), LÜE teorisi (Graen, 1976) ve sosyal değişim teorisi (Blau, 1964) de daha iyi performansın lider-üye arasındaki uyum ve etkileşimin adil olduğunda ortaya çıkacağını işaret etmiştir. Çeşitli çalışmalarda da lider-üye etkileşiminin çalışan performansını artırmak için önemli bir motivasyon kaynağı olduğu belirtilmiştir (Graen ve UhlBien, 1995). Benzer şekilde Huang, Wang ve You (2015) da liderliğin performans için güçlü bir faktör olduğunu işaret etmiştir. Alan yazında yüksek kaliteli LÜE'nin olduğu örgütlerde sadakat ve güvenin yaygınlaştığl; düşük kaliteli LÜE'nin hissedildiği örgütlerde de kişiler arası iliş̧kilerde güvensizliğin olduğunu saptayan çalışmalarla karşılaş1lmıştır. Volmer vd. (2012) de örgüt ikliminin olumlu bir hale gelmesinde liderin çalışanlarına daha fazla zaman ayırması ve onların gelişimi için rehberlik ettiğini işaret etmiştir. Böylece çalışanlarda iş doyumu ve örgüte olan bağl1lı̆̆ın da arttığı ifade edilmiştir. Ancak alan yazında LÜE ve çalışan performansı arasındaki ilişkilere yönelik tutarsız sonuçların olduğu da görülmüştür. Kimi araştırmalarda kaliteli LÜE'nin çalışanların performanslarını artırdığı (Agarwal vd., 2012; DeConinck, 2011; Graen ve Uhl-Bien, 1995; Li, Sanders ve Frenkel, 2012) görülürken kimilerinde de herhangi bir olumlu ilişkinin olmadığı (Harris vd., 2009) tespit edilmiştir. Bu olumsuzluğun altında yatan sebepler arasında katılımcıların değerleri, kişilikleri ve deneyimleri düşünülebilir (Huang, Chan, Lam ve Nan, 2010). Bu konuda Dunegan, Uhl-Bien ve Duchon (2002) çalışmalarında LÜE'nin üstlerinden yönlendirme ve motivasyon ihtiyaçlarının düşük olduğu rutin özellikleri yoğun olan işlerdeki çalışanların performanslarını fazla etkilemediği görülmüştür. $\mathrm{Bu}$ durum LÜE ile performans ilişkisinde durumsal özelliklerin farklı sonuçlar üretebileceğini işaret etmiştir.

$\mathrm{Bu}$ çalışmanın yapılmasının ardında LÜE ve çalışan performansı arası ilişkilere yönelik tutarsız bulgularla karşılaşılması önemli rol oynamıştır. Ayrıca ilgili değişkenleri birlikte inceleyen çalışmalar olsa da, bu çalışmaların bir bütün halinde ele alınarak çözümlenmemesi bir eksiklik olarak düşünülmektedir. Kapsamlı bir bakış açısı geliştirebilmek için birbirinden bağımsız çalışmaların bulguları tek başına yeterli olmamaktadır. Çalışmalar çeşitli sebeplerden dolayı çok sayıda sınırlılıklar içerisinde gerçekleştirilmektedir. Her çalışmanın gerçekleştirildiği şartlar doğal olarak birbirinden farklı olabilmektedir. Bu nedenle ilgili değişkenlere yönelik benzer çalışma bulgularının birlikte değerlendirilerek analiz edilmesi alan yazına katkı sunacaktır. Bu bağlamda bu çalışmanın amacı 01.01.2000-31.12.2020 tarihleri arasında Türkiye'de lider-üye etkileşimi ile çalışan performansı arasındaki ilişkiyi inceleyen çalışma 
bulgularının meta-analiz yöntemi ile birleştirilmesidir. Bu doğrultuda aşağıdaki soruların cevabı aranmıştır:

1. Meta-analizde yer alan araştırmaların betimsel özelliklerine göre dağılımları nasildir?

2. Lider-üye etkileşimi ile çalışan performansı arasındaki ilişkinin genel etki büyüklüğü nedir?

\section{Yöntem}

Günümüzde herhangi bir konuda yapılan çok sayıda çalışma ile karşılaşmak mümkündür. Bu çalışmalardan elde edilen bulguları inceleyerek bir sonuca ulaşmak ise oldukça zaman alabilmektedir. Diğer bir ifadeyle zaman kaybının en aza indirilmesi için çalışmaların sistematik bir analize tutulması gerekli görülmektedir. Kısaca, diğer analizlerin analizi olarak ifade edilen meta-analiz, farklı çalışmalarda ulaşılan çok sayıda bulguyu tutarlı ve uyumlu şekilde bütünsel olarak değerlendirerek nicel veriler sunar (Cohen, Wolkowitz ve Even, 2000: 222; Littel, Corcoran ve Pillai, 2008). Çalışmanın yönteminden dolayı etik kurul izni alınmamıştır.

\subsection{Verilerin Toplanması}

Araştırmada lider-üye etkileşimi ve çalışan performansı arasındaki ilişkiyi inceleyen çalışmalar yer almıştır. Bu kapsamda Aralık ayı 2020 yılı içerisinde YÖK Ulusal Tez Merkezi, ULAKBIM Ulusal Veri Tabanı ve Google Akademik üzerinde araştırmalar yapılmıştır. Araştırmada "lider-üye etkileşimi", "leader-member exchange", "LMX", "performans", "performance" anahtar kelimeleri ile 20 y1llı bir zaman dilimini ifade eden 01.01.200031.12.2020 tarihleri arasında yapılan tez (yüksek lisans-doktora) ya da makalelere ulaşılmıştır. Ayrıca ulusal alan yazın incelendiğinde ilgili değişkenlerin birlikte ele alındığı ilk çalışmanın 2007 yılında gerçekleştirildiği de görülmüştür. Bu çalışmalarda performans ile çalışanların bireysel performansı vurgulanmıştır. Ulaşılan çalışmaların tezden üretilmiş olması durumunda sadece tez ya da makale değerlendirilmeye alınmıştır. Çalışmaların araştırmaya dâhil edilme ölçütleri aşağıda sunulmuştur.

1. Çalışmanın 01.01.2000-31.12.2020 arasında yapılmış olması,

2. Çalışmanın lider-üye etkileşimi ve çalışan performansını incelemesi,

3. Çalışmanın Türkiye'de yapılması olması,

4. Etki büyüklüğünü belirleyebilmek için yeterli istatistiki bilgilerin bulunması (örneklem büyüklüğü, korelasyon katsayısı vb.).

Yapılan incelemeler sonucunda başlık, özet, dizin ya da anahtar kelimelerde lider-üye etkileşimi ve performans kelimelerinin yer aldığ 30 çalışma ile karşılaşılmıştır. 30 çalışma arasında birinin takım performansı ile LÜE arasındaki ilişkiyi incelediği, iki çalışmada $r$ değerinin olmadığı ve dört çalışmanın ise tezden üretildiği görülmüştür. $\mathrm{Bu}$ nedenle araştırmadan yedi çalışma çıkartılmıştır. Araştırmada yer alan 23 çalışmaya ilişkin betimsel veriler Tablo 1'de sunulmuştur. 
Tablo 1. Araștırma grubunda yer alan çalıșmaların betimsel verileri

\begin{tabular}{|c|c|c|c|c|}
\hline$\overline{\text { Sira }}$ & Yazar, Y1l & $\begin{array}{l}\text { Yayın } \\
\text { Türü }\end{array}$ & Örneklem Grubu & $\begin{array}{c}\text { Örneklem } \\
\text { Sayıs1 }\end{array}$ \\
\hline 1 & Aslaner ve Artan, 2019 & Makale & Özel sektör çalışanı & $532 *$ \\
\hline 2 & Bal Taştan, 2014 & Makale & Özel sektör çalıșanı & 190 \\
\hline 3 & Beltekin, 2019 & Tez (D.) & Calıșan & 702 \\
\hline 4 & Cerit, 2012 & Makale & Öğretmen & 253 \\
\hline 5 & Cevrioğlu, 2007 & Tez (D.) & Öğretim görevlisi & 189 \\
\hline 6 & Çiçek ve Çiçek, 2020 & Makale & Özel-kamu çalışanları ve yöneticileri & 381 \\
\hline 7 & Doğru, 2016 & Tez (D.) & Özel-kamu sektörü çalışanı & 314 \\
\hline 8 & Gökgöz, 2016 & Tez (YL.) & Çalışan ve yönetici & 357 \\
\hline 9 & Gündoğdu Özel, 2018 & Tez (YL.) & Çalışan ve yönetici & 403 \\
\hline 10 & Gürbüz ve Ayhan, 2017 & Makale & Çalışan ve yönetici & 227 \\
\hline 11 & Kalyar, 2017 & Tez (D.) & Kamu çalışanı & 378 \\
\hline 12 & Kandemir, 2016 & Tez (YL.) & Kamu çalışanı ve yöneticileri & 439 \\
\hline 13 & Karaman, 2018 & Tez (YL.) & Öğretmen & 449 \\
\hline 14 & Karayel, Akkoç ve Birer, 2018 & Makale & Kamu çalışanı & $223 *$ \\
\hline 15 & Özer, 2019 & Makale & Hemșire & 203 \\
\hline 16 & Özkan, 2017 & Tez (YL.) & Özel sektör çalıșanı & 121 \\
\hline 17 & Özutku, Ağca ve Cevrioğlu, 2008 & Makale & Çalışan ve yönetici & 221 \\
\hline 18 & Turgut, Tokmak ve Ateș, 2015 & Makale & Öğretmen & 471 \\
\hline 19 & Uludağ, 2019 & Makale & Kamu çalıșanı & $406^{*}$ \\
\hline 20 & Uzun, 2019 & Tez (YL.) & Öğretmen & 558 \\
\hline 21 & Üçler ve Bal Taştan, 2017 & Makale & Çalışan ve yönetici & $242 *$ \\
\hline 22 & Veli, 2019 & Tez (YL.) & Özel sektör çalıșanı & 216 \\
\hline 23 & Yadmaa, 2020 & Tez (YL.) & Çalıșan & 220 \\
\hline
\end{tabular}

*Yüksek lisans ya da tezden üretilmiş makale

Tablo 1 incelendiğinde 12 lisansüstü tez (4 doktora- 8 yüksek lisans) ve akademik dergilerde yayımlanmış 11 makalenin meta-analizde yer aldığı görülmektedir. Ayrıca metaanalizin çalışma grubunun 7695 kişiden oluştuğu hesaplanmıştır. Çalışmaların yayımlanma tarihleri ele alındığında ise 01.01.2000-31.12.2010 tarihleri arasında iki, 01.01.2011-31.12.2020 tarihleri arasında da 21 çalışmanın gerçekleştirildiği göze çarpmıştır. Bu durum son yıllarda kavramlara arası ilişkiye yönelik bir ilginin olduğunun göstergesi olarak düşünülebilir.

\subsection{Verilerin Analizi}

Araştırmada lider-üye etkileşimi ve çalışan performansı arasındaki ilişkiyi inceleyen 23 çalışma meta-analiz yöntemi ile birleştirilmiştir. Araştırmada öncelikle çalışmalara ilişkin betimsel analiz (yazar, yıl, yayın türü, örneklem grubu, örneklem sayısı) frekans değerleri verilerek yapılmıştır. Ardından da değişkenler arası ilişkiye yönelik etki büyüklükleri metaanaliz yöntemi ile hesaplanmıştır. Meta-analiz CMA 3.0 programı aracılığıyla gerçekleştirilmiştir.

Meta-analiz çalışmalarında değişkenlere ilişkin etki büyüklükleri hesaplanır. Etki büyüklükleri yorumlanırken korelasyonal etki büyüklügü sınıflandırması dikkate alınmıştır. Bu sinıflandırmada .00-.30 "zayıf düzeyde", .31-.50 "orta düzeyde", .51-80 "yüksek düzeyde" ve .81 ve üzeri de "çok yüksek düzeyde" olarak yorumlanmıştır (Cohen, Manion ve Morrison, 2007). Ayrıca bu çalışmada etki büyüklüğü "Hedge's g” değeri ile hesaplanırken anlamlılık ise .05 düzeyinde belirlenmiştir. Meta-analiz çalışmalarında etki büyüklüğü belirlenirken geçerliğin yeterli düzeyde olması önemlidir. Bu tür çalışmalarda geçerlik üzerinde en olumsuz etki bırakan unsur yayın yanlılı̆̆ı olarak belirtilebilir (Rothstein, Sutton ve Borenstein, 2006). Mevcut araştırmada geçerlik, yayın yanlılığı üzerinden ele alınmıştır. Bu doğrultuda huni grafiği dağılımları ve çeşitli istatistiki analiz sonuçları incelenmiştir. Huni grafiğinde yer alan içi boş dairelerin merkezdeki çizgi etrafında olabildiğince simetrik olarak dağılması yayın yanlılığının olmadığ 1 şeklinde yorumlanmaktadır. Ardından yayın yanlılığı için Rosenthal'ın Güvenli T testi değeri, Begg ve Mazumdar Sira Korelasyonları ve Egger'in Doğrusal Regresyon değeri incelenmiştir. Meta-analizde uygulanacak modeli belirlemek için ise homojenlik/heterojenlik durumu araştırılmıştır. $\mathrm{Bu}$ doğrultuda $\mathrm{Q}$ ve $\mathrm{I}^{2}$ değerleri irdelenmiştir. $\mathrm{Bu}$ değerlerin sonucuna 
göre sabit ya da rastgele etkiler modeline karar verilmiştir. Cooper, Hedges ve Valentine'e (2009) göre $I^{2}$ değerinin \% 25 olması düşük, \% 50 olması orta ve \% 75 olması da yüksek düzeyde heterojen dağılımı işaret etmektedir.

\section{Bulgular}

Meta-analiz sonucunda ulaşılan etki büyüklüğüne ilişkin farklı iki modelde ulaşılan değerler ve homojenlik/heterojenlik testi değerleri Tablo 2'de sunulmuştur.

Tablo 2. Etki büyüklükleri ve homojenlik/heterojenlik testi değerleri

\begin{tabular}{|c|c|c|c|c|c|c|c|c|c|c|}
\hline \multirow{2}{*}{ Model } & \multirow{2}{*}{$n$} & \multirow{2}{*}{$\begin{array}{l}\text { Ortalama } \\
\text { Etki } \\
\text { Büyüklüğü }\end{array}$} & \multirow{2}{*}{$Z$} & \multirow{2}{*}{$\begin{array}{l}\text { Standart } \\
\text { Hata }\end{array}$} & \multicolumn{2}{|c|}{$\begin{array}{c}\text { \% 95'lik Güven } \\
\text { Aralığ } 1 \\
\end{array}$} & \multirow{2}{*}{$s d$} & \multirow{2}{*}{$Q$} & \multirow[b]{2}{*}{$p$} & \multirow{2}{*}{$I^{2}$} \\
\hline & & & & & $\begin{array}{c}\text { Alt } \\
\text { Sinır }\end{array}$ & $\begin{array}{l}\text { Üst } \\
\text { Sinır }\end{array}$ & & & & \\
\hline $\begin{array}{c}\text { Sabit } \\
\text { Etkiler } \\
\text { Modeli }\end{array}$ & 23 & .465 & 44.024 & .021 & .448 & .483 & 22 & 468.661 & .00 & 95.306 \\
\hline $\begin{array}{l}\text { Rastgele } \\
\text { Etkiler } \\
\text { Modeli }\end{array}$ & 23 & .440 & 8.860 & & .352 & .520 & 22 & & & \\
\hline
\end{tabular}

Tablo 2 incelendiğinde meta-analizde yer alan çalışmalara yönelik etki büyüklüğü sabit etkiler modeline göre .465; rastgele etkiler modeline göre de .440 olarak hesaplanmıştır. Gerçek etki değerinin belirlenmesi için homojenlik/heterojenlik durumu belirlenmelidir. Bu doğrultuda $\mathrm{Q}(s d=22)$ değerinin 468.661 olduğu görülmüştür $(\mathrm{p}<.01)$. Q değerinin ki-kare tablosunda yer alan .05 güven düzeyinde 22 serbestlik derecesinde 33.924 değerinin üzerinde olması verilerin heterojen bir yapıda olduğunu işaret etmiştir. Ayrıca $\mathrm{I}^{2}$ değerinin \% 95.30 olarak hesaplanması da yüksek düzeyde heterojenliği desteklemiştir. Bu bulgular göz önünde bulundurulduğunda rastgele etkiler modeli kullanılmıştır. Bu doğrultuda çalışmanın etki değeri .44 olarak tespit edilmiştir. Ayrıca Tablo 3'de araştırmada yer alan çalışmaların etki büyüklükleri sunulmuştur.

Tablo 3. Rastgele etkiler modelinde çalışmaların bireysel etki büyüklüğü

\begin{tabular}{|c|c|c|c|c|c|c|}
\hline \multirow[b]{2}{*}{ Model } & \multirow[b]{2}{*}{ Çalışma Adı } & \multicolumn{5}{|c|}{ Çalışmaların İstatistiki Bilgileri } \\
\hline & & $\begin{array}{c}\text { Etki } \\
\text { Büyüklüğü }\end{array}$ & $\begin{array}{l}\text { Alt } \\
\text { Sinır }\end{array}$ & Üst Sinır & $Z$ & $p$ \\
\hline & Aslaner ve Artan, 2019 & 0.602 & 0.545 & 0.654 & 16.014 & 0.000 \\
\hline & Bal Taştan, 2014 & 0.594 & 0.493 & 0.679 & 9.351 & 0.000 \\
\hline & Beltekin, 2019 & 0.590 & 0.540 & 0.636 & 17.917 & 0.000 \\
\hline & Cerit, 2012 & 0.517 & 0.420 & 0.602 & 9.048 & 0.000 \\
\hline & Cevrioğlu, 2007 & 0.270 & 0.132 & 0.397 & 3.776 & 0.000 \\
\hline & Çiçek ve Çiçek, 2020 & 0.314 & 0.220 & 0.402 & 6.318 & 0.000 \\
\hline & Doğru, 2016 & 0.393 & 0.295 & 0.483 & 7.325 & 0.000 \\
\hline & Gökgöz, 2016 & 0.498 & 0.416 & 0.572 & 10.285 & 0.000 \\
\hline & Gündoğdu Özel, 2018 & 0.690 & 0.635 & 0.738 & 16.959 & 0.000 \\
\hline & Gürbüz ve Ayhan, 2017 & 0.400 & 0.285 & 0.504 & 6.341 & 0.000 \\
\hline & Kalyar, 2017 & 0.394 & 0.305 & 0.476 & 8.066 & 0.000 \\
\hline & Kandemir, 2016 & 0.599 & 0.535 & 0.656 & 14.441 & 0.000 \\
\hline & Karaman, 2018 & 0.772 & 0.732 & 0.807 & 21.652 & 0.000 \\
\hline & Karayel, Akkoç ve Birer, 2018 & 0.380 & 0.262 & 0.487 & 5.934 & 0.000 \\
\hline & Özer, 2019 & 0.551 & 0.447 & 0.640 & 8.766 & 0.000 \\
\hline & Özkan, 2017 & 0.308 & 0.137 & 0.461 & 3.458 & 0.001 \\
\hline & Özutku, Ağca ve Cevrioğlu, 2008 & 0.148 & 0.016 & 0.275 & 2.201 & 0.028 \\
\hline & Turgut, Tokmak ve Ateş, 2015 & 0.300 & 0.215 & 0.380 & 6.696 & 0.000 \\
\hline & Uludağ, 2019 & 0.557 & 0.486 & 0.621 & 12.617 & 0.000 \\
\hline & Uzun, 2019 & 0.090 & 0.007 & 0.172 & 2.126 & 0.034 \\
\hline & Üçler ve Bal Taştan, 2017 & 0.157 & 0.032 & 0.278 & 2.447 & 0.014 \\
\hline & Veli, 2019 & 0.226 & 0.095 & 0.349 & 3.356 & 0.001 \\
\hline & Yadmaa, 2020 & 0.305 & 0.180 & 0.420 & 4.641 & 0.000 \\
\hline Rastgele & & 0.440 & 0.352 & 0.520 & 8.860 & 0.000 \\
\hline
\end{tabular}


Tablo 3'e göre araştırmada bulunan çalışmaların tamamının etki büyüklüğünün pozitif yönlü olması, genel etkinin pozitif yönlü olduğunu göstermektedir. Ayrıca meta-analiz sonucunda ulaşılan etki büyüklüğünün geçerliğinin göstergesi olarak yayın yanlılı̆̆ 1 durumu ortaya konulmalıdır. Bu doğrultuda huni grafiği üzerinde çalışmaların nasıl bir dağılım gösterdiği Şekil 2'de sunulmuştur.

Şekil 1. Huni saç1lım grafiği

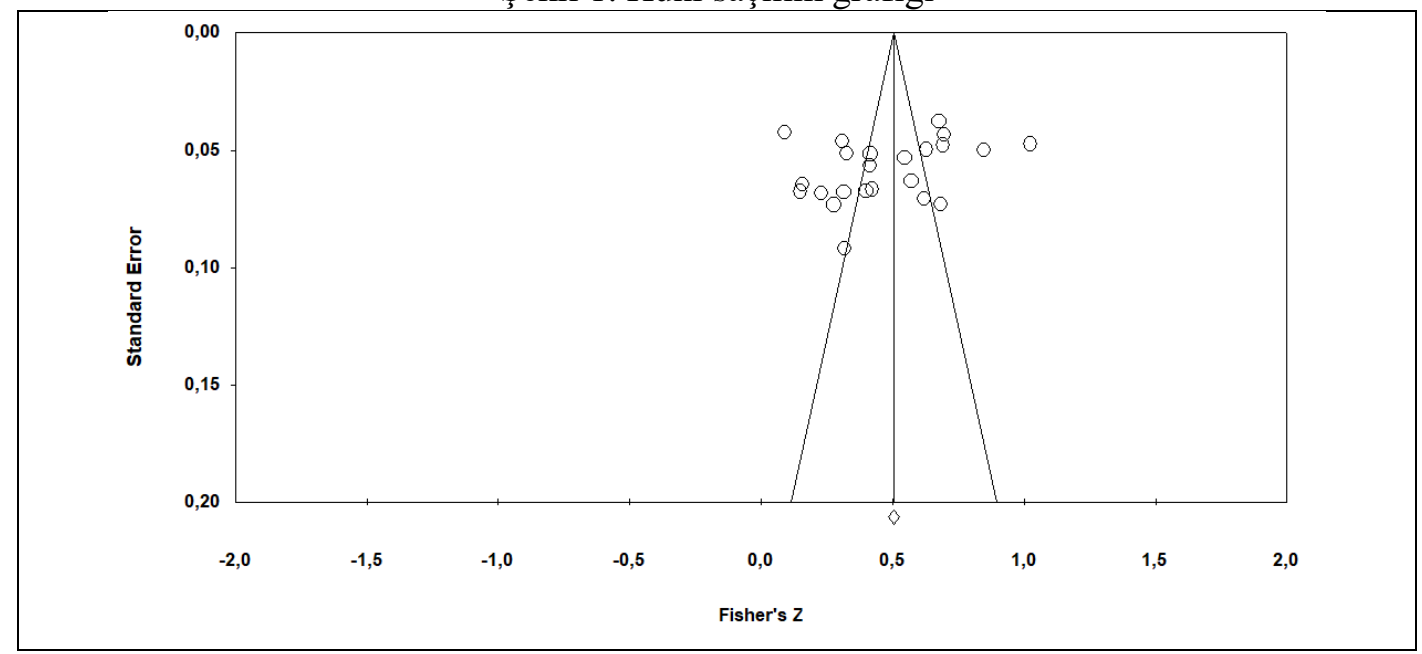

Şekil 1 incelendiğinde çalışmaların merkezde yer alan çizginin etrafında simetrik olarak dağıldığı görülmektedir. Dinçer (2014) yayın yanlılığı olmamasının göstergelerinden biri olarak çalışmaların ortada ki çizginin çevresinde asimetrik olmayan bir biçimde toplanmasının gerektiğini belirtmiştir. Ayrıca araştırmada yayın yanlılığı Rosenthal'ın Güvenli T testi değeri açısından da ele alınmıştır. Rosenthal'ın Güvenli T testi incelendiğinde 23 çalışmanın yer aldığ 1 meta-analizde $p$ değerinin anlamsızlık oluşturabilmesi için en az 363 çalışmanın mevcut araştırmadaki çalışmalara zıt değerler üretmesi gerektiğini işaret etmiştir. Ayrıca Begg ve Mazumdar Sira Korelasyonlarında Kendall'ın Tau katsayısı $(-.20$ ve $p=.161)$ ile Egger'in Doğrusal Regresyon değerinin $(p=.155 ;>.05)$ de anlamlı olmadığı tespit edilmiştir. Bu bulgular araştırmada yayın yanlılığ

\section{Sonuç, Tartışma ve Öneriler}

$\mathrm{Bu}$ çalışmada lider-üye etkileşimi ve çalışan performansı arasındaki ilişkiler meta-analiz yöntemi ile incelenmiştir. Çalışmada belirli ölçütlere göre belirlenen 23 araştırmanın bireysel ve genel etki büyüklükleri hesaplanmıştır. Ardından yayın yanlılığı Rosenthal'ın Güvenli T testi, Begg ve Mazumdar Sira Korelasyonları ve Egger'in Doğrusal Regresyon değeri ile incelenmiştir. Ulaşılan değerler yayın yanlılığının olmadığını işaret etmiştir. Ayrıca çalışmada yer alan araştırmaların etki büyüklüklerinin birleştirilmesinde homojenlik/heterojenlik testi sonucunda rastgele etkiler meta-analiz modeli kullanılmıştır.

Çalışmanın ilk bulgusu meta-analizde yer alan araştırmaların betimsel özelliklerine ilişkindir. Analiz edilen araştırmaların yayın türü açısından dengeli bir dağılıma sahip olduğu belirlenmiştir. $\mathrm{Bu}$ araştırmalardan dördü doktora ve sekizi yüksek lisans tezi olmak üzere toplam 12 lisansüstü tez olduğu görülmüştür. Ayrıca 11 araştırma da makale türünde yayımlanmıştır. Araştırmaların gerçekleştirildiği çalışma grupları incelendiğinde kamu ve özel sektör çalışanları ve yöneticilerinin çoğunlukta olduğu ifade edilebilir. Bazı çalışmalarda da çalışanların hangi sektör mensubu oldukları belirlenememiştir. Araştırmaların yayımlanma dönemleri ele alındığında ise iki araştırmanın 2000-2010 yılları ve 21 araştırmanın da 20112021 yılları arasında yapıldığı görülmüştür. Bu durum son yıllarda lider-üye etkileşimi ile çalışan performansı arasındaki ilişkilere odaklanan bir yaklaşımın geliştiğini işaret etmektedir. Ek olarak meta-analizde ulaşılan çalışma grubunun 7695 kişiden oluştuğu tespit edilmiştir. 
Meta-analiz sonucunda ulaşılan bulgular lider-üye etkileşimi ile çalışan performansı arasında pozitif yönlü ve orta düzeyde ilişkiler olduğunu işaret etmiştir. Bu bulgunun çeşitli çalışma bulguları ile uyumlu olduğu görülmüştür (Bal Taştan, 2014; Beltekin, 2019; Cerit, 2012; Gökgöz, 2016; Lee vd., 2019; Markham, Yammarino, Murry ve Palanski, 2010; Özer, 2019; Uludağ, 2019). Bu çalışmalar arasında Aslaner ve Artan'ın (2019) özel sektör çalışanları üzerine araştırmasında yöneticileri ile olumlu etkileşim içerisinde olan çalışanların bireysel performanslarının yükseldiği tespit edilmiştir. Benzer şekilde Cogliser, Schriesheim, Scandura ve Gardner (2009) da lider-üye etkileşiminin çalışan performansını etkileyen önemli bir değişken olduğunu işaret etmiştir. Ayrıca bazı çalışmalarda da değişkenler arası pozitif yönlü ilişkilerin varlığının daha zayıf olduğu da belirlenmiştir (Anand vd., 2018; Golden ve Veiga, 2008; Haynie, Cullen, Lester, Winter ve Svyantek, 2014; Kuvaas, Buch, Dysvik ve Haerem, 2012; Li, Sanders ve Frenkel, 2012; Özutku, Ağca ve Cevrioğlu, 2008; Uzun, 2019; Üçler ve Bal Taştan, 2017). Özellikle lider ile izleyenleri arasındaki ilişki ele alınırken kültürel farklılıkların yansımaları da bir unsur olarak düşünülebilir. Şöyle ki LÜE üzerine geliştirilen ilk modellerin Batı kültürü çerçevesinde ele alınması mevcut çalışmanın örnekleminde yer alan katılımcıların performansı üzerindeki ilişkiden daha farklı bir bulgu olabilirdi. Bu konuda Rockstuhl, Dulebohn, Ang ve Shore'un (2012) 23 ülkede gerçekleştirilen LÜE ile ilgili olan çalışmaları inceledikleri meta-analiz araştırması farklı değişkenler üzerine farklı bulgular üretmiştir. Ancak bu değişkenler arasında yer alan performansın Hofsted'in kültür üzerine yaptığı çalışmalarında ifade ettiği güç mesafesi düşük ve güç mesafesi yüksek olan ülkelerde de benzer sonuçlar ortaya koyduğudur. Diğer bir ifadeyle bireyselliğin ön planda olduğu ülkeler ile toplumcu bir anlayışın hâkim olduğu Türkiye gibi ülkelerde LÜE ile performans arasında pozitif yönlü bir ilişki saptanmıştır. Bu bulgunun da mevcut çalışma bulgusunu desteklediği görülmüştür. Baltaş'a (2015) göre Türk kültüründe yönetimin dinamikleri çeşitli unsurlar açısından Batı kültürüne göre farklılıklara sahip olsa da hem ulusal hem de uluslararası alan yazına göre lider-üye ilişkisinin niteliğinin performans üzerinde etki gösterdiği tespit edilmiştir.

Alanyazın bütünsel olarak ele alındığında lider-üye etkileşimi ve çalışan performansı arasında olumlu yönlü ilişkilerin olduğu ifade edilebilir. Örgütsel etkililiğinin sağlanmasında örgütteki insan kaynaklarının alan uzmanlıkları kadar birbirleri ile olan ilişkileri de belirleyici bir etmen olabilir. Özellikle örgüt yöneticisinin liderlik davranışları ile çalışanlarını etkilemesi örgütsel etkililik için önemli bir unsurdur. Lider ile çalışanlar arasındaki etkileşimin niteliğinin hem bireysel hem de örgütsel çok sayıda olumlu ya da olumsuz çıttıyı ortaya koyacağ 1 düşünülebilir. Zaten çeşitli çalışmalarda da lider-üye etkileşiminin çalışanların davranışları üzerindeki etkisi işaret edilmiştir (Akman, 2017; Alev ve Taş, 2020; Lee vd., 2019; Tekin, 2018; Uhl-Bien vd., 2000; Wang vd., 2015). Örgütlerde liderin çalışanlarına rahat hissedebilecekleri ortamları sağlaması, özellikle bireysel ilişkilerde çalışanlara kendilerini değerli hissettirmesi ve saygı duyması çalışanların örgüte ve lidere vefakârlık ve sadakat duygularını geliştirmelerini sağlayabilir. Zaten, Bal Taştan (2014) olumlu bir lider çalışan ilişkisinde karşl1ıklı sadakat ve saygının da olduğunu ve bu durumun çalışan performansını da artırdığını işaret etmiştir. Benzer şekilde Uludağ (2019) da, lider-üye ilişkisindeki profesyonel saygının performansı olumlu etkileyen bir değişken olduğunu vurgulamıştır.

Bir örgütün amaçlarına ulaşmasında maddi-manevi çok sayıda unsurun katkısı bulunmaktadır. Özellikle insan kaynaklarının niteliği ve aralarındaki ilişkinin kalitesi örgütün varlığını sürdürebilmesi için kritik bir etmendir. Araştırmada ulaşılan bulgulara dayanarak örgütün lideri ile çalışanlar arası etkileşimin çalışanların performansı üzerinde etki gösteren önemli bir değişken olduğu sonucuna ulaşılmıştır. Bu sonuç olumlu bir lider-üye etkileşiminin çalışanların performanslarını artırırken, olumsuz bir etkileşimin de çalışanların performanslarını düşüreceği şeklinde yorumlanabilir. Çalışmada çeşitli sınırlılıkların olduğu belirtilebilir. Metaanalizde yer alan araştırmaların sadece ulusal alanyazında yayımlanan tez ve makale olması bir sınırlılık olarak düşünülmüştür. Her ne kadar araştırma kriterleri belirlenmiş olsa da çalışmada uluslararası makale, tez, bildiri vb. araştırmaların olmaması bir eksikliktir. Ayrıca nicel teknikler ile elde edilen bulguların, değişkenler arası ilişkilerin derinlemesine incelenerek 
nedensel etkilerin ortaya çıkartılması zorlaştırabilmesi de diğer bir sınırlılık olarak ifade edilebilir. Çalışma bulguları doğrultusunda araştırmacılara $(i)$ ilgili değişkenler arası ilişkilerin farklı çalışan örneklemleri (kamu-özel, eğitim, sağlık, güvenlik sektörü vb.) üzerinden incelenmesi, (ii) ilgili değişkenler arası ilişkilerin boylamsal olarak ele alınması, (iii) değişkenler arası ilişkilerin dinamiklerini keşfetmeye yönelik öncül-ardıl bireysel-örgütsel değişkenlerle olan ilişkilerinin araştırılması, (iv) değişkenler arası ilişkilerin çeşitli ülkeler bağlamında incelenerek kültürel farklı1ıkların anlamlılığının araştırılması önerilmektedir. Ayrıca uygulamaya dönük olarak (v) lider-üye etkileşiminin gelişimi açısından iletişim becerileri konusunda hem yöneticilerin hem de çalışanların eğitim almaları (vi) lider-üye etkileşimini artıracak sosyal etkinlikler düzenlenmesi tavsiye edilmektedir.

\section{Kaynakça}

Meta-analizde yer alan çalı̧̧malar *ile gösterilmiştir.

Agarwal, U. A., Datta, S., Blake-Beard, S., ve Bhargava, S. (2012). Linking LMX, innovative work behaviour and turnover intentions: the mediating role of work engagement. Career Development International, 17(3), 208-230.

Akman, Y. (2017). Sosyal sermaye ve öğretmenlerin okulları ile özdeşleşmeleri ilişkisinde lider-üye etkileşiminin aracılık etkisi. Bartın Üniversitesi Eğitim Fakültesi Dergisi, 6(1), 263-281.

Alev, S., ve Taş, D. (2020). Lider-üye etkileşimi, tükenmişlik ve örgütsel bağl1lık arasındaki ilişki: öğretmenler üzerine bir araştırma. Anemon Muş Alparslan Üniversitesi Sosyal Bilimler Dergisi, 8(5), 1611-1619.

Anand, S., Hu, J., Vidyarthi, P., ve Liden, R. C. (2018). Leader-member exchange as a linking pin in the idiosyncratic deals-performance relationship in workgroups. The Leadership Quarterly, 29, 698-708.

Arar, K., ve Abu Nasra, M. (2019). Leadership style, occupational perception and organizational citizenship behavior in the Arab education system in Israel. Journal of Educational Administration, 57(1), 85-100.

Ariani, D. W. (2012). Leader-member exchanges as a mediator of the effect of job satisfaction on affective organizational commitment: an empirical test. International Journal of Management, 29, 46-56.

*Aslaner, F., ve Artan, İ. H. (2019). Pozitif psikolojik sermayenin lider-üye etkileşimi vasıtasıyla bireysel performansı etkilemedeki rolü: perakende sektöründe bir araştırma. Business and Management Studies: An International Journal, 7(4), 1657-1689.

*Bal Taştan, S. (2014). Examination of the relationship between leadermember exchange (LMX) quality and employee job performance in the moderating context of perceived role ambiguity. Interntional Journal of Management Economics and Business, 10(22), 211-233.

Baltaş, A. (2015). Türk kültüründe yönetmek, yerel değerlerle küresel başarılar kazanmak. İstanbul: Remzi Kitabevi.

Bass, B. (1985). Leadership and performance beyond expectations. New York: Free Press.

*Beltekin, E. (2019). Lider-üye etkileşimi algisı ile bireysel performans arasındaki ilişkide işe yönelik motivasyonun aracllı rolü: Gençlik hizmetleri ve spor il müdürlükleri üzerine bir araştırma (Yayınlanmamış yüksek lisans tezi). Erciyes Üniversitesi, Kayseri.

Bilgin Yurdaöz, A. (2018). Meslek liselerindeki yöneticilerin gösterdiği etik liderlik tipi ile ögretmen performansı arasındaki ilişkinin incelenmesi (Yayınlanmamış yüksek lisans tezi). Recep Tayyip Erdoğan Üniversitesi, Rize. 
Blau, P. (1964). Exchange and power in social life. New York: John Wiley.

*Cerit, Y. (2012). Lider üye etkileşimi ile öğretmenlerin performansları arasındaki ilişki. Balıkesir Üniversitesi Sosyal Bilimler Enstitüsü Dergisi, 15(28), 33-46.

*Cevrioğlu, E. (2007). Lider-üye etkileşimi ile bireysel ve örgütsel sonuçlar arasındaki ilişki: Ampirik bir araştırma (Yayınlanmamış Doktora Tezi). Afyonkarahisar Kocatepe Üniversitesi, Afyonkarahisar.

Cogliser, C. C., Schriesheim, C. A., Scandura, T. A., ve Gardner, W. L. (2009). Balance in leader and follower perceptions of leader-member exchange: Relationships with performance and work attitudes. The Leadership Quarterly, 20, 452-465.

Cohen, J. (1988). Statistical power analysis for the behavioral sciences. NJ: Lawrence Earlbaum Associates.

Cohen, J., Walkowitz, J., ve Ewen, R. B. (2000). Introductory statistics for the behavioral sciences. Orlando: Harcourt Brace College Publishers.

Cooper, H., Hedges, L. V. ve Valentine, J. C. (2009). The handbook of research synthesis and meta analysis. New York: Sage.

Çalışkan, A. (2018). Dönüşümcü liderliğin iş performansına etkisi: lider üye etkileşimi ve örgütsel bağlılığın aracılık rolü. Toros Üniversitesi İISBF Sosyal Bilimler Dergisi, 5(8), 104140.

Çetin, Ş., Korkmaz, M., ve Çakmakçı, C. (2012). Dönüşümsel ve etkileşimsel liderlik ile liderüye etkileşiminin öğretmenlerin örgütsel vatandaşlık davranışı üzerindeki etkisi. Kuram ve Uygulamada Eğitim Yönetimi, 18(1), 7-36.

*Çiçek, B., ve Çiçek, A. (2020). İşyeri nezaketsizliğinin yaratıcı çalışan performansı üzerindeki etkisi: lider-üye etkileşiminin arac1lık rolü. İş ve İnsan, 7(2), 267-282.

DeConinck, J. B. (2011). The effects of leader-member exchange and organizational identification on performance and turnover among salespeople. Journal of Personal Selling ve Sales Management, 31, 21-34.

Dienesch, R., ve Liden, R. (1986). Leader-member exchange model of leadership: a critique and further development. Academy of Management Review, 11(3), 618-634.

*Doğru, Ç. (2016). Algılanan örgütsel destek ve lider-üye etkileşiminin bağlamsal performansa etkileri: Ankara'da bankacılık sektöründe bir araştırma (Yayımlanmamış doktora tezi). Gazi Üniversitesi, Ankara.

Dulebohn, J. H., Bommer, W. H., Liden, R. C., Brouer, R., ve Ferris, G. R. (2012). A metaanalysis of the antecedents and consequences of leader-member exchange: Integrating the past with an eye toward the future. Journal of Management, 38, 1715-1759.

Dunegan, K. J., Uhl-Bien, M., ve Duchon, D. (2002). LMX and subordinate performance: the moderating effects of task characteristics. Journal of Business Psychology, 17, 275-285.

Gerras, S. J. (1992). The effect of cognitive busyness and nonverbal behaviors on trait inferences and leader-member exchange judgments. Dissertation abstracts international, 53(7-B), 3819-3820.

Golden, T. D., ve Veiga, J. F. (2008). The impact of superior-subordinate relationships on the commitment, job satisfaction, and performance of virtual workers. The Leadership Quarterly, 19, 77-88.

*Gökgöz, S. (2016). Lider üye etkileşiminin algılanan iş performansina etkisinde örgütsel vatandaşlık davranışının rolü (Yayımlanmamış Yüksek Lisans Tezi). Türk Hava Kurumu Üniversitesi, Ankara. 
Graen, G. B. (1976). Role-making process within complex organization. In M. D. Dunnette, (Ed.), Handbook of industrial and organizational psychology, (pp. 1201-1245). Chicago: Rand McNally.

Graen, G. B., ve Uhl-Bien, M. (1995). Relationship-based approach to leadership: Development of leader-member exchange (LMX) theory of leadership over 25 years: Applying a multilevel multi-domain perspective. The Leadership Quarterly, 6, 219-247.

*Gündoğdu Özel, E. (2018). Iş̧ performansının artırlmasında motivasyonel faktörlerin rolü; yenilikçi davranışın aracılık rolü: mersin bölgesi özel bankalarında bir uygulama (Yayımlanmamış yüksek lisans tezi). Toros Üniversitesi, Mersin.

*Gürbüz, S., ve Ayhan, Ö. (2017). Lidere yakın olmanın dayanılmaz hafifliği: lider-üye etkileşimi, görev performansı, tecrübe ve terfi edebilirlik arasındaki ilişkilerin testi. Türk Psikoloji Dergisi, 32(80), 1-15.

Harris, K. J., Wheeler, A. R., ve Kacmar, K. M. (2009). Leader-member exchange and empowerment: direct and interactive effects on job satisfaction, turnover intentions, and performance. The Leadership Quarterly, 20, 371-382.

Haynie, J. J., Cullen, K. L., Lester, H. F., Winter, J., ve Svyantek, D. J. (2014). Differentiated leader-member exchange, justice climate, and performance: Main and interactive effects. The Leadership Quarterly, 25, 912-922.

Huang, X., Chan, S. C. H., Lam, W., ve Nan, X. (2010). The joint effect of leader-member exchange and emotional intelligence on burnout and work performance in call center in China. The International Journal of Human Resource Management, 21, 1124-1144.

Huang, J., Wang, L., ve Xie, J. (2014). Leader - member exchange and organizational citizenship behavior: the roles of identification with leader and leader's reputation. Social Behavior and Personality, 42, 1699-1712.

Huang, J., Wang, Y., ve You, X. (2015). The job demands-resources model and job burnout: The mediating role of personal resources. Current Psychology, 35, 562-569.

*Kalyar, M. N. (2017). Psikolojik sermaye, lider-üye etkileşimi ve motivasyon ara değişkenleri bağlamında etik liderliğin yaratıcılık ve performans üzerindeki etkisi (Yayımlanmamış doktora tezi). İnönü Üniversitesi, Malatya.

*Kandemir, G. (2016). Lider-üye etkileşiminin bireysel performansa etkisinde örgütsel bağhllı̆̆ın rolü (Yayımlanmamış yüksek lisans tezi). Türk Hava Kurumu Üniversitesi, Ankara.

*Karaman, E. (2018). Lider-üye etkileşimi ile bireysel performans arasındaki ilişski: çorum ilindeki ilk ve orta dereceli okullarda bir araştırma (Yayımlanmamış yüksek lisans tezi). Türk Hava Kurumu Üniversitesi, Ankara.

*Karayel, M., Akkoç, İ, ve Birer, İ. (2018). Örgütsel destek, sosyal destek ve lider desteğinin iş performansına etkisinde lider-üye etkileşiminin aracılık rolü. Işletme Fakültesi Dergisi, 19(2), 301-333.

Khorakian, A., ve Sharifirad, M. S. (2019). Integrating implicit leadership theories, leadermember exchange, self-efficacy, and attachment theory to predict job performance. Psychological Reports, 122(3), 1117-1144.

Kuvaas, B., Buch, R., Dysvik, A., ve Haerem, T. (2012). Economic and social leader-member exchange relationships and follower performance. The Leadership Quarterly, 23, 756-765. 
Lee, A., Thomas, G., Martin, R., ve Guillaume, Y. (2019). Leader-Member exchange (LMX) ambivalence and task performance: the cross-domain buffering role of social support. Journal of Management, 45(5), 1927-1957.

Li, X., Sanders, K., ve Frenkel, S. (2012). How leader-member exchange, work engagement and HRM consistency explain Chinese luxury hotel employees' job performance. International Journal of Hospitality Management, 31(4), 1059-1066.

Liden, R., ve Maslyn, J. (1998). Multidimensionality of leader member exchange: an empirical assessment through scale development. Journal of Management, 24(1), 43-72.

Lipsey, M. W., ve Wilson, D. B. (2001). Practical meta-analysis. Applied Social Research Methods Series (Vol. 49). Thousand Oaks, CA: Sage publications.

Littel, H. J., Corcoran, J., ve Pillai, V. (2008). Systematic reviews and meta-analysis. New York: Oxford University Press.

Markham, S. E., Yammarino, F. J., Murry, W. D., ve Palanski, M. E. (2010). Leader-member exchange, shared values, and performance: Agreement and levels of analysis do matter. The Leadership Quarterly, 21, 469-480.

Martin, R., Guillaume, Y., Thomas, G., Lee, A., ve Epitropaki, O. (2016). Leader-member exchange (LMX) and performance: a meta-analytic review. Personnel Psychology, 69, 67121.

Mazur, K. (2012). Leader-member exchange and individual performance. The meta-analysis. Management, 16(2), 40-53.

Meng, F., ve Wu, J.(2015). Merit pay fairness, leader-member exchange, and job engagement: evidence from Mainland China. Review of Public Personnel Administration, 35, 47-69.

Michael, D. (2011). Supportive supervisor communication as an intervening influence in the relationship between LMX and employee job satisfaction, turnover intentions, and performance. Journal of Behavioral Studies in Business, 4, 1-28.

*Özer, Ö. (2019). Hemşirelerde lider-üye etkileşimi ve çalışan performansının incelenmesi. Sağllk ve Hemşirelik Yönetimi Dergisi, 1(6), 11-21.

*Özkan, M. (2017). Lider-ast etkileşim düzeyinin astların iş performansı üzerine etkisi (Yayımlanmamış yüksek lisans tezi). Hacettepe Üniversitesi, Ankara.

Öztürk, N., ve Şahin, S. (2017). Eğitim örgütlerinde örgüt kültürü ve öğretmen liderliği: liderüye etkileşiminin arac1lık rolü. Illkögretim Online, 16(4), 1451-1468.

*Özutku, H., Ağca, V., ve Cevrioğlu, E. (2008). Lider-üye etkileşimi teorisi çerçevesinde, yönetici-ast etkileşimi ile örgütsel bağl1lık boyutları ve iş performans arasındaki ilişki: Ampirik bir inceleme. Atatürk Üniversitesi İktisadi ve idari Bilimler Dergisi, 22(2), 193-210.

Rockstuhl, T., Dulebohn, J. H., Ang, S., ve Shore, L. M. (2012). Leader-member exchange (LMX) and culture: A meta-analysis of correlates of LMX across 23 countries. Journal of Applied Psychology, 97, 1097-1130.

Rothstein, H. R., Sutton, A. J., ve Borenstein, M. (Eds.). (2005). Publication bias in metaanalysis: Prevention, assessment and adjustments. West Sussex: John Wiley ve Sons.

Quade, M. J., McLarty, B. D., ve Bonner, J. M. (2020). The influence of supervisor bottom-line mentality and employee bottom-line mentality on leader-member exchange and subsequent employee performance. Human Relations, 73(8) 1157-1181.

Scandura, T. A., ve Pellegrini, E. K. (2008). Trust and leader-member exchange: a closer look at relational vulnerability. Journal of Leadership ve Organizational Studies, 15, 101-110. 
Schriesheim, C. A., Neider, L. L., Scandura, T. A., ve Tepper, B. J. (1992). Development and preliminary validation of a new scale (LMX-6) to measure leader-member exchange in organizations. Educational and Psychological Measurement, 52, 135-147.

Shore, L. M., Tetrick, L. E., Lynch, P., ve Barksdale, K. (2006). Social and economic exchange: Construct development and validation. Journal of Applied Social Psychology, 36(4), 837867.

Tastan, S. B., ve Davoudi, S. M. M. (2015). An examination of the relationship between leadermember exchange and innovative work behavior with the moderating role of trust in leader: a study in the Turkish context. Social and Behavioral Sciences,181, 23-32.

Tekin, E. (2018). Lider-üye etkileşiminin çalışan performans1 üzerindeki etkisinde örgütsel vatandaşlık davranışının aracı rolü. Karadeniz Teknik Üniversitesi Sosyal Bilimler Enstitüsü Sosyal Bilimler Dergisi, 8(16), 343-363.

*Turgut, H., Tokmak, İ. ve Ateş, M. F. (2015). Lider-üye etkileşiminin işgören performansına etkisinde çalışanların örgütsel adalet algılarının rolü. Çankırı Karatekin Üniversitesi İ̈BF Dergisi, 5(2), 417-442.

Tutar, H., ve Altıöz, M. (2010). Örgütsel iklimin işgören performansı üzerine etkisi: Ostim imalât işletmeleri çalışanları üzerine bir araştırma. Ankara Üniversitesi Siyasal Bilgiler Fakültesi Dergisi, 65(2), 195-218.

Uhl-Bien, M., Graen, G. B., ve Scandura, T. A. (2000). Implications of leader-member exchange (LMX) for strategic human resource management systems: relationships as social capital for competitive advantage. Research in Personnel and Human Resources Management, 18, 137-186.

*Uludağ, G. (2019). Lider üye etkileşiminin işgören performansına etkisi üzerine bir alan araştırmas1. Atatürk Üniversitesi Sosyal Bilimler Enstitüsü Dergisi, 23(2), 719-739.

*Uzun, S. A. (2019). Illkokul öğretmenlerinin lider üye etkileşimine ilişkin algılamalarının görev ve bağlamsal performansları üzerindeki etkisini belirlemede iş tatmininin aracı rolü: kayseri ilinde bir uygulama (Yayımlanmamış yüksek lisans tezi). Nevşehir Hacı Bektaş Veli Üniversitesi, Ankara.

*Üçler, Ç., ve Taştan, S. B. (2017) Investigating the relations of psychological contract, organizational transparency and leader-member exchange with employee performance behaviors. Journal of Behavior at Work, 2(2), 89-107.

*Veli, M. F. (2019). Tekstil sektöründe lider üye etkileşiminin çalışanların örgütsel bağlllık ve performansları üzerine etkisi (Yayımlanmamış yüksek lisans tezi). Beykent Üniversitesi, İstanbul.

Volmer, J., Spurk, D., ve Niessen, C. (2012). Leader-member exchange (LMX), job autonomy, and creative work involvement. The Leadership Quarterly, 23(3), 456-465.

Walumbwa, F. O., Cropanzano, R., ve Goldman, B. M. (2011). How leader-member exchange influences effective work behaviors: social exchange and internal-external efficacy perspectives. Personnel Psychology, 64(3), 739-770.

Wang, H., Law, K. S., Hackett, R. D., Wang, D., ve Chen, Z. X. (2005). Leader-member exchange as a mediator of the relationship between transformational leadership and followers' performance and organizational citizenship behaviour. Academy of Management Journal, 48(3), 420-432.

Wang, Z., Xu, H., Liu, Y., ve Jiang, F. (2015). The antecedents and consequences of leadermember exchange differentiation: A resource perspective. In academy of management proceedings. Academy of Management. 
Wang, Y., Chen, C. C., Lu, L., Eisenberger, R., ve Fosh, P. (2018). Effects of leader-member exchange and workload on presenteeism. Journal of Managerial Psychology, 33(7), 511523.

*Yadmaa, N. (2020). Lider üye etkileşiminin kariyer memnuniyeti ve bireysel performans üzerindeki etkisi: Moğolistan sağllk kurumlarında bir araştırma (Yayımlanmamış yüksek lisans tezi). Trakya Üniversitesi, Edirne.

\section{ETİK ve BIILIMSEL İLKELER SORUMLULUK BEYANI}

$\mathrm{Bu}$ çalışmanın tüm hazırlanma süreçlerinde etik kurallara ve bilimsel atıf gösterme ilkelerine riayet edildiğini yazar(lar) beyan eder. Aksi bir durumun tespiti halinde Afyon Kocatepe Üniversitesi Sosyal Bilimler Dergisi'nin hiçbir sorumluluğu olmayıp, tüm sorumluluk makale yazarlarına aittir. 